\title{
The new landmarks, findings and signs in optical coherence tomography
}

\author{
Burak Turgut* and Tamer Demir \\ Department of Ophthalmology, Faculty of Medicine, Firat University, Elazig 23119, Turkey
}

\begin{abstract}
Spectral domain optical coherence tomography (SD-OCT) is a useful non-invasive imaging method which is used in the diagnosis and follow-up of various macular diseases. Photoreceptor disruption detected with OCT might be demonstrated the loss of integrity or absence of external limiting membrane, ellipsoid zone and interdigitation zone. It has been considered that the disruptions of these outer retinal layers or zones are highly correlate with lower visual acuity in various retinal diseases. Newly, current OCT findings and signs include outer retinal tubulation, hyperreflective dots/spots, flyer saucer, perifoveal cupping, focal choroidal excavation, dipping sign, choroidal macrovessel, pearl necklace sign, cystoid foveal degeneration, outer retina-choroid complex splitting, foveal pseudocyst, domeshaped macula and brush border pattern. These might be important indicators for prognosis and response in various macular diseases.
\end{abstract}

\section{Introduction}

Spectral domain optical coherence tomography (SD-OCT) is a very useful non-invasive imaging method which is used in the diagnosis and follow-up of diseases involving the macula, such as age-related macular degeneration (AMD), diabetic maculopathy, central serous chorioretinopathy (CSCR), epiretinal membrane (ERM), various macular dystrophies/maculopathies and macular hole, etc. It provides detailed information for the evaluation of drusen, intraretinal/subretinal hemorrhage or fluid and detachment of retina pigment epithelium (RPE) or retina [1-4]. OCT can reveal ERM, choroidal neovascular membrane (CNVM), fibrovascular lesion, fibrotic scar, hard exudate, nerve fiber infarct and macular or optic disk drusen, intraretinal or subretinal fluid and cystoid cavities [1-4]. These common OCT findings are well known. Currently, due to the developments in OCT technology and the frequent use of OCT in ophthalmology, currently, some new OCT findings have been reported day after day. The aim of this study is to present new pathological or abnormal findings in SDOCT and to emphasize the causes of these.

\section{Normal OCT findings and histological landmarks}

In a normal colored spectral domain OCT scan, the high reflectivity signals represented by yellow and red colors, come from the retinal nerve fiber layer (RNFL), plexiform layers, internal limiting membrane (ILM), junction between inner and outer segments of photoreceptors (IS/OS), RPE and choriocapillaris complex. The low reflectivity signals represented by black and blue colors belong to the nuclear layers. The normal vitreous gel is not visible in color OCT imaging because it is optically transparent and it seems black color (Figure 1) [1,2].

The external limiting membrane (ELM) (Figure 1A) is located at the boundary between the nuclei and the inner segments of the photoreceptors, and points out the junctional complexes between Müller cells and the photoreceptors [1-4].

The ellipsoid zone (EZ) (Figure 1B) is considered to be formed mainly by mitochondria within the ellipsoid layer of the outer portion of the inner segments of the photoreceptors. However, it was previously known as the junction between the photoreceptor IS/OS). In a normal fovea, EZ is located closer to ELM than RPE [1-4].

The interdigitation zone (IZ) (Figure 1B) is considered to be the contact cylinders formed by the apices of the RPE cells that encase
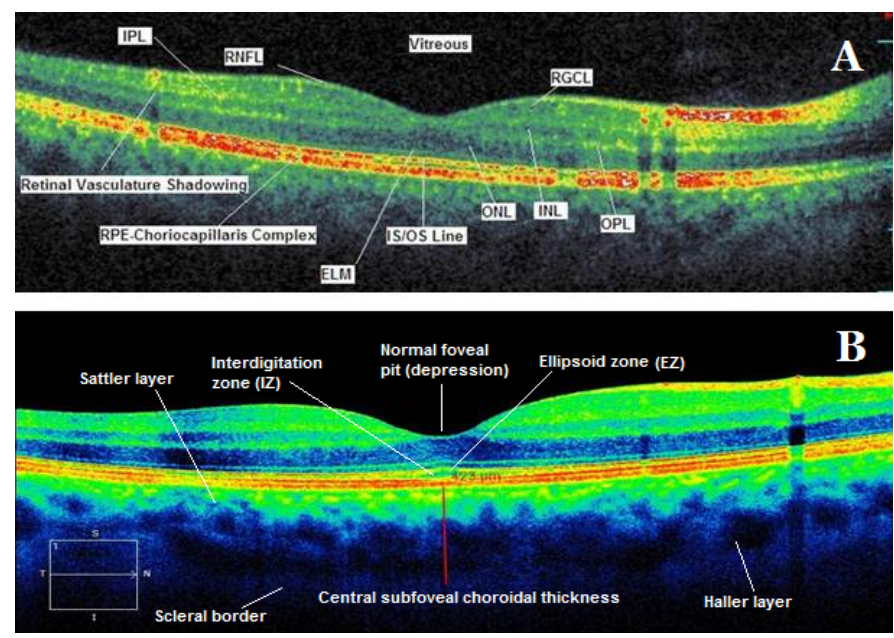

Figure 1. Spectral domain (A) and enhanced depth imaging (B) optical coherence tomography scans with main retinal and choroidal histology landmarks from a healthy subject. RPE: retina pigment epithelium; RNFL: retinal nerve fiber layer; RGCL: retinal ganglion cell layer; INL: inner nuclear layer; IPL: inner plexiform layer; ONL: outer nuclear layer; OPL: outer plexiform layer; ELM: external limiting membrane; IS/OS: inner segment/outer segment junction line, EZ: ellipsoid zone, IZ: interdigitation zone.

Correspondence to: BurakTURGUT, MD, Associate Professor of Ophthalmology, Firat University, Faculty of Medicine, Department of Ophthalmology, 23119, Elazig, Turkey, Tel: Tel: +90 424 2333555; Fax: +90 424 2388096; E-mail: drburakturgut@gmail.com

Key words: optical coherence tomography, new findings, signs, macular diseases, prognosis, disruption, external limiting membrane, ellipsoid zone, interdigitation zone

Received: April 07, 2016; Accepted: April 29, 2016; Published: May 04, 2016 
part of outer segments of the cones. It was previously called the cone outer segment tips (COST) and rod outer segment tips (ROST), and its differentiation from RPE layer is difficult.

The RPE line (Figure 1A) is formed by the RPE and Bruch's membrane and choroiocapillaris and it is thicker in the fovea compared to other regions [1-4].

\section{Common conventional abnormal findings}

In an OCT scan with macular pathology, the high reflectivity signals except above mentioned retinal layers may due to the reduced retinal thickness, ERM, CNVM, fibrovascular lesion, fibrotic scar, hard exudate, nerve fiber infarct and macular or optic disk drusen. Intraretinal or subretinal fluid and cystoid cavities seem as low reflectivity/unreflectivity areas. High reflectivity is a feature of and pigmentation of the scar tissue, example, a disciform scar [1,2].

In dry AMD, disruption or absence of the EZ has been shown to correlate with visual outcomes and disease severity and it has been demonstrated that an intact EZ in the patients with geographic atrophy has higher visual acuity. In the other hand, it has been reported that the baseline EZ integrity was as a positive prognostic factor for visual outcomes following intravitreal anti-vascular endothelium growth factor (AntiVEGF) injections in wet-AMD. In the eyes with diabetic macular edema (DME), EZ disruption at the fovea was reported as an important predictor of visual acuity. Additionally, it was reported that EZ disruption was correlated with poorer visual outcomes following macular hole or ERM surgery.

The integrity of the IZ is also predictor of visual acuity outcome following surgeries for ERM, retinal detachment (RD) and macular hole. These data shows that disruption, discontinuity or the loss of integrity of the ELM, EZ and IZ bands in OCT point out a damage or disruption of the photoreceptors in various retinal diseases $[3,4]$.

Morever, it was hypothesized a stepwise order for importance of these lines in degenerative retinal diseases: first at the IZ, followed by the EZ and finally the ELM line [5-19].

However, it was demonstrated that the ELM is the first structure recovering following successful macular hole surgery, and that the recovery of ELM is a sign of intact photoreceptors and Müller cells. Additionally, it was reported that EZ recovery is restricted to areas with intact ELM, whileas IZ recovery is observed only in eyes with an intact EZ and ELM line following the surgeries for macular hole and epiretinal membrane [11-18]. These mean that an intact foveal ELM is essential for the complete restoration of the other photoreceptor microstructures [7-19].

In the recent studies, it was considered that the presence of undisturbed ELM is a positive predictor of visual outcome in treatment of AMD and DME $[9,10]$. A shorter ELM length before treatment was demonstrated to be associate with a lesser degree of change in visual acuity after AMD treatment [9].

After successful macular hole restoration, presence of disrupted ELM was associated with poor visual acuity and restoration of the EZ was restricted to areas where the ELM was also fully recovered, suggesting that restoration of the ELM is closely associated with that of the EZ [11-18].

In eyes with retinal detachment, preservation of the ELM postoperatively was correlated with better postoperative visual acuity and the restoration of the photoreceptor layer $[5,15]$. Photoreceptor disruption might be demonstrated using OCT as loss of integrity or absence of ELM, EZ and IZ. It has been considered that the disruptions of these the outer retinal layers are highly correlate with lower visual acuity and retinal sensitivity in various retinal diseases [9-19].

\section{New abnormal OCT findings and signs (Table 1)}

Outer retinal tubulations or cysts (Figure 2A): Outer retinal tubulation (ORT) is distinctive OCT finding firstly described Zweifel et al. It is formed histologically by interconnecting tubes, including degenerate photoreceptors and enveloping Müller cells. They are not seen in healthy retinae. ORTs have been identified at outer retinal layers or next to photoreceptors in AMD, pseudoksantoma elasticum, Bietti's crystalline retinopathy, multifocal choroiditis and uveitis with CNVM, CSCR, pattern dystrophy and choroideremia [20-23]. ORT is a different type of other cystic structures. It should be distinguishing from intraretinal fluid cysts, cystic cavities, pseudo cysts located at outer retinal layers. Intraretinal fluid cysts in cystoid macular edema (CME) have the arrangement as petalloid manner while as ORTs are randomly arranged at the macula. ORTs have often in the branched structure in contrast to subretinal fluid. Pseudocysts are also hyporeflective intraretinal cysts. However, they are viewed in inner nuclear layer $[24,25]$. ORTs are round hyporeflective lesions surrounded by an hyperreflective ring. It may contain a few focal hyperreflective spots in contrast to the completely hyporeflective retinal cystoid lesions. ORT has a hyperreflective border while as the cyst has no hyperreflective border. ORT is more refractory to anti-vascular endothelial growth factor (AntiVEGF) therapy compared to the cysts and is associated with poor visual outcome. ORT is always located at the level of the outer nuclear layer [20-23].

Outer retinal tubulation is a finding long lasting macular disease. It is typically observed at areas of previous outer retinal damage, overlying fibrotic/fibrovascular scar or retinal atrophy or near to neovascular fibrotic lesion in the patients with AMD. It has been considered that it might be an indicator of failure of the photoreceptor support system (RPE and choroid) as in choroideremia and some some inherited retinal degenerations [20-23]. Since they are not the indicator for an ongoing neovascular or exudative activity and, they do not require treatment [20-23].
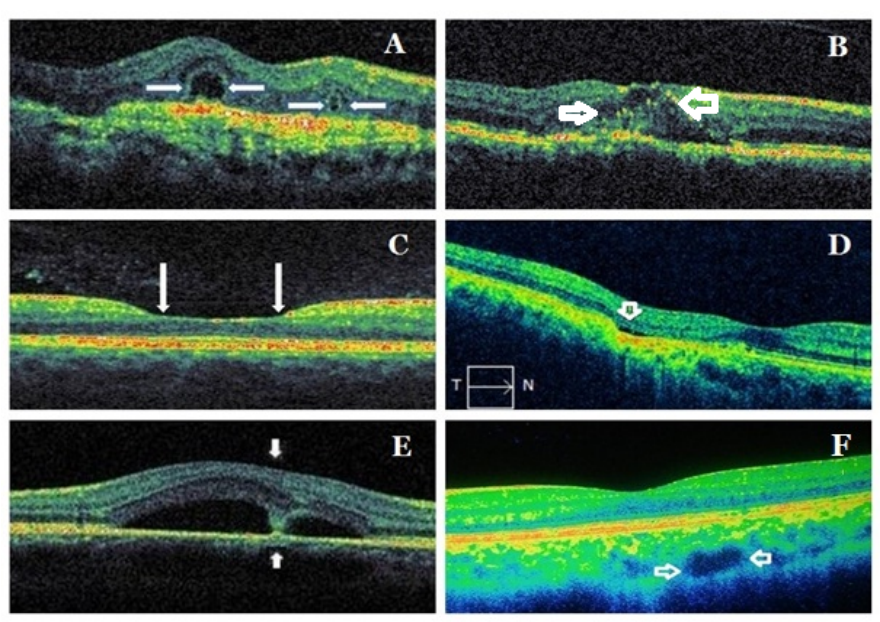

Figure 2. Samples from new signs/patterns/findings in spectral domain optical coherence tomography: ORT (A), HRD (B), perifoveal cupping (C), FCE (D), dipping sign (E), choroidal macrovessel (F). Arrows indicate specifically each entity. ORT: outer retinal tubulation; HRD: hyperreflective dots; FCE: focal choroidal excavation. 
Table 1. OCT entities/signs, their associations and clinical significances.

\begin{tabular}{|c|c|c|}
\hline OCT finding/entity/sign & Associated Diseases & Clinical significance \\
\hline ORT & $\begin{array}{l}\text { AMD, pseudoxanthoma elasticum, Bietti's crystalline retinopathy, } \\
\text { multifocal choroiditis and experimental uveitis with CNVM, } \\
\text { CSCR, Choroideremia }\end{array}$ & $\begin{array}{l}\text { Refractory/nonresponsive to AntiVEGF therapy } \\
\text { A finding of longterm-lasting CNVM } \\
\text { Poor visual outcome }\end{array}$ \\
\hline HRD & AMD, DME, RVO, CSCR, uveitis, macular telengiectasia & $\begin{array}{l}\text { Disseappearing following AntiVEGF treatment } \\
\text { A marker of inflammatory response } \\
\text { A marker of the breakdown of the BRB }\end{array}$ \\
\hline Flyer saucer & Antimalarial drug induced maculopathy & $\begin{array}{l}\text { Perifoveal loss of the photoreceptor IS/OS junction } \\
\text { A possible sign of preclinical stage of antimalarial drug toxicity }\end{array}$ \\
\hline Perifoveal cupping & Antimalarial drug induced maculopathy & $\begin{array}{l}\text { Perifoveal inner retinal thinning } \\
\text { A possible predictor for impending/early antimalarial related maculopathy }\end{array}$ \\
\hline FCE & $\begin{array}{l}\text { AMD, CSCR, ERM, PCV, BVMD, VKHD, multifocal choroiditis } \\
\text { and punctate inner choroidopathy, focal retinochoroiditis, } \\
\text { foveoschisis, torpedo maculopathy, MEWDS, combined } \\
\text { hamartoma of the retina and RPE }\end{array}$ & $\begin{array}{l}\text { Usually stationary } \\
\text { Rarely choroidal neovascularization }\end{array}$ \\
\hline Dipping sign & CSCR & $\begin{array}{l}\text { Acute cases } \\
\text { Fibrinous exudate } \\
\text { Dipping or tenting at the outer surface of detached neurosensory retina }\end{array}$ \\
\hline Choroidal macrovessel & $\begin{array}{l}\text { Associated no retinal abnormality or hyperpigmentation of the } \\
\text { RPE, debris in the subretinal space, and changes in the outer } \\
\text { nuclear layer thickness }\end{array}$ & $\begin{array}{l}\text { The differential diagnosis from the choroidal vascular lesions and choroidal } \\
\text { hemangioma, subretinal parasite, vortex varix, retinochoroidal anastomosis, } \\
\text { anomalous posterior ciliary vessels and ocular trauma and inflammatory disorder }\end{array}$ \\
\hline Pearl necklace sign & AMD, DME, RVO, retinal arterial macroaneurysm, Coats disease & $\begin{array}{l}\text { A sign of chronic exudative maculopathy } \\
\text { A sign of a particularly excessive macular edema }\end{array}$ \\
\hline CFD & AMD, Diabetic maculopathy, RVO, uveitis, CSCR & $\begin{array}{l}\text { A predictor for lower success rate in treatment } \\
\text { Chronic event. } \\
\text { A cause of pseudo cystoid foveal edema }\end{array}$ \\
\hline ORCC splitting & BVMD & Specific OCT sign of Pseudohypopion Stage \\
\hline Foveal pseudo cyst & $\begin{array}{l}\text { Previous vitreoretinal surgery with perfluorocarbon liquid } \\
\text { Subretinal subfoveal liquid retantion }\end{array}$ & $\begin{array}{l}\text { A serious complication } \\
\text { Toxic to the RPE and photoreceptors } \\
\text { Necessary for surgical removal of subfoveal retained liquid }\end{array}$ \\
\hline Dome- shaped macula & $\begin{array}{l}\text { High Myopia, posterior staphyloma } \\
\text { Serous macular detachment }\end{array}$ & $\begin{array}{l}\text { Anteriorly configuration of the macula } \\
\text { Macular convexity } \\
\text { Difficult identification in ophthalmoscopy }\end{array}$ \\
\hline Brush-border pattern & CSCR & $\begin{array}{l}\text { Accumulation of waste products in photoreceptor outer segments } \\
\text { Elongation of photoreceptor outer segments } \\
\text { Chronic cases }\end{array}$ \\
\hline
\end{tabular}

AMD: age related macular degeneration; PCV: polypoidal vasculopathy; RVO: retinal venous occlusion; CSCR: central serous chorioretinopathy; CNVM: choroidal neovascular membrane; DME: diabetic macular edema; ERM: epiretinal membrane; BVMD: Best' vitelliform macular dystrophy; VKHD: Vogt Koyanagi Harada Disease; MEWDS: multiple evanescent white dot syndrome; RPE: retina pigment epithelium; IS/OS: inner segment/outer segment; BRB: blood-retina barrier; OCT: optical coherence tomography; VEGF: vascular endothelial growth factor; ORT: outer retinal tubulation; HRD: hyperreflective dots; FCE: focal choroidal excavation, ORCC: outer retina-choroid complex; CFD: cystoid foveal degeneration.

Hyperreflective spots or dots (Figure 2B): Hyperreflective spots or dots (HRD) are new findings previously unseen in OCT demonstrated firstly by Coscas et al. [26]. It has been reported that they might seem in different retinal diseases, including AMD, DME, retinal venous occlusion (RVO), CSCR, uveitis and macular telangiectasia [26-40]. HRDs are not visible in any monochromatic and angiographic photos. The HRDs are scattered, punctiform, small in size, mainly located in the outer retinal layers and/or around pockets of fluid accumulation and are typically not confluent $[26,27]$. Costas et al hypothesized that HRD were detected in the majority of patients affected by exudative AMD could be inflammatory activated and swelled cells or activated microglia cells because they may spread in all retinal layers in contrast to hard exudates, that they rapidly disappear after antiVEGF or antiinflammatory treatment $[26,27]$. They considered that inflammation plays in the role at the pathogenesis of AMD and suggested that the presence of HRDs could affect the prognosis and treatment decisions, particularly in the patients with AMD.

Although etiology of HRD is not clear, there are various theories of pathogenesis of HRD. They might be caused focal accumulations of pigment or lipofuscin granules, small intraretinal proteins or lipid/ lipoprotein exudates/deposits/extravasation due to the breakdown of the blood-retinal barrier (BRB), derived the degenerated photoreceptors or the macrophages phagosited them [26-40]. It has been reported that HRDs were the first features to disappear or to reduce significantly after anti-VEGF treatment in patients with both focal DME and diffuse DME. Therefore, it has been hypothesized that HRDs represent a clinical marker of inflammatory response [28-40].

Flyer saucer sign: This sign was firstly described as an emerging finding of early antimalarial maculopathy by Chen et al using OCT in patients with at 2010. Its main characteristics are the loss of the normal foveal depression, perifoveal thinning of the outer nuclear layer, an ovoid appearance of the central fovea, preservation of the outer retinal structures and photoreceptor IS/OS junction in the central fovea, an apparent posterior displacement of the inner retinal structures toward RPE, and perifoveal loss of the photoreceptor IS/OS junction [41,42]. It is not pathognomonic nor necessary for the diagnosis of antimalarial maculopathy. However, its detection in SDOCT might be an emerging finding of early antimalarial maculopathy.

Perifoveal cupping (Figure 2C): In a recent study, we observed "perifoveal inner retinal thinning" as a new sign in the romathologic patients using antimalarial drug and we called it as "perifoveal cupping". We considered that this entity detected with SD-OCT might be a predictor for impending antimalarial related maculopathy in the absence of visual field defect. As a support to our findings, in a previous study, it was detected an appearance of a broadened foveal base and also thinning of the inner retinal layer on SD-OCT in the patients using antimalarial drug without fundus and visual field changes. 
Perifoveal cupping or a broadened foveal base might indicate early hydroxychloroquine retinopathy $[43,44]$.

Focal choroidal excavation (Figure 2D): Focal choroidal excavation (FCE) is a new choroidal entity, which can only be detected with OCT. It was firstly described by Jampol et al using OCT in $2006[45,46]$. FCE is characterized by focal concavity at the RPEchoriocapillaris line in the choroid in an OCT scan, with a good visual acuity, and normal appearance of the overlying retina. In the FCE cases, there is no history of trauma and current or prior retinal or choroidal vascular or infectious disease $[45,46]$. FCE affects Bruch's membraneRPE-choriocapillaris complex line and photoreceptors. It is considered that this lesion often remains stable. However, some lesions may be related to development the CNVM [47-50]. It has been reported that FCE may occur in various macular diseases such as AMD, CSCR, ERM, CNVM, polypoidal choroidal vasculopathy (PCV), Best vitelliform macular dystrophy (BVMD), Vogt-Koyanagi-Harada Disease (VKHD), multifocal choroiditis and punctate inner choroidopathy, focal retinochoroiditis, foveoschisis, torpedo maculopathy, multiple evanescent white dot syndrome (MEWDS), combined hamartoma of the retina and retinal pigment epithelium [47-59].

The pathogenesis of the FCE is not well defined. However, it is considered that FCE could be an embryonic developmental disorder, or an acquired pathology. Some authors hypothesize that FCE is a congenital malformation while as others theorize that it might due to the failure of chorioretinal development in the embryonic stage, micro staphyloma, congenital focal choroidal dysplasia, focal choroidal atrophy caused by congenital or acquired choroiditis [47-50]. They might occur as cone-shaped, bowl-shaped type the mixed type in OCT [48].

Dipping sign (Figure 2E): Dipping (tenting down) sign may be observed in some acute CSCR patients. It is characterized by dipping or tenting at the outer surface of detached neurosensory retina due to hyperreflective material accumulation such as subretinal fibrin or fibrinous exudate connecting the detached neurosensory retina and RPE at its opposite $[60,61]$.

Choroidal macrovessel (Figure 2F): Choroidal macrovessel, the abnormal choroidal vessel was firstly described by Lima et al using indocyanine green angiography (ICGA) [62]. Recently, it has been also reported the findings in enhanced depth imaging (EDI) and en face (EF) imaging in OCT of the choroidal macrovessel. It may be associated no retinal abnormality or hyperpigmentation of the RPE, debris in the subretinal space, and changes in the outer nuclear layer thickness $[62,63]$. The choroidal macrovessel should be distinguished from choroidal hemangioma, subretinal parasite, vortex varix, retinochoroidal anastomosis, anomalous posterior ciliary vessels $[62,63]$.

Pearl necklace sign (Figure 3A): The pearl necklace sign detected with SD-OCT is characterized by a contiguous ring of small hyperreflective dots lining in the inner wall of cystoid spaces located in the OPL. It is considered that it may represent lipid-laden macrophages [64].

The pearl necklace sign should be distinguishing from ORT, which is located deeper in the outer nuclear layer of the retina. In ORT, the hyperreflective ring is continuous and homogeneous, whileas the contiguous hyperreflective dots are as small foci in the pearl necklace sign. Both entity have also different pathogenesis. It is considered that ORT might be a result of focal disruption of the photoreceptor layer
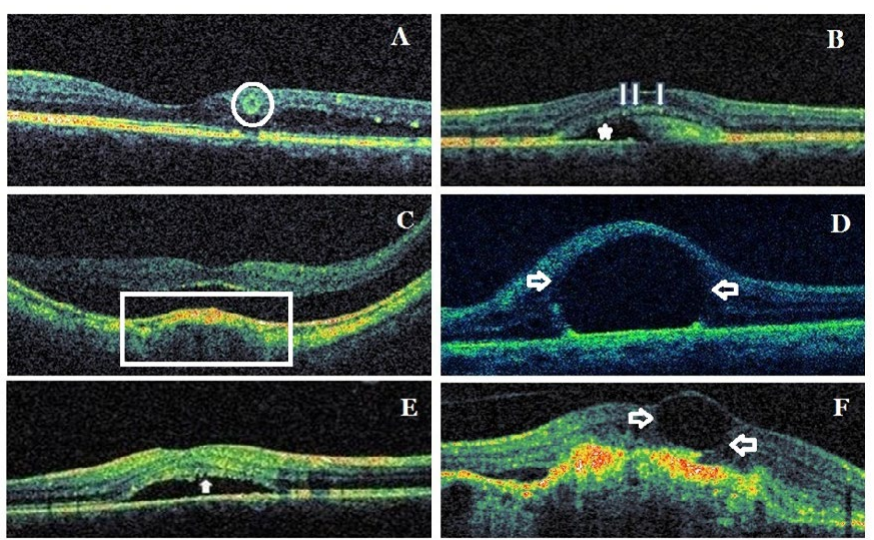

Figure 3. Samples from new signs/patterns/findings in spectral domain optical coherence tomography: Pearl necklace sign (circle) (A), ORCC splitting (arrows and asterisk)(B), dome-shaped macula (frame) (C), foveal pseudocyst (arrows) (D), brush-border pattern (arrow) (E), CFD (arrows) (F). ORCC: outer retina-choroid complex; CFD: cystoid foveal degeneration.

[64].

Outer retina-choroid complex splitting (Figure 3B): OCT can show a splitting of outer retina-choroid complex (ORCC) or broadening of ORCC. The splitting is between photoreceptor outer segments, RPE and Bruch membrane. It may occur in the patients with best vitelliform macular dystrophy [65].

Foveal pseudo cyst (Figure 3D): The presence of subfoveal perfluorocarbon liquid (PFCL) after vitreoretinal surgery can cause the appearance of cystoid foveal edema. Subretinal PFCL at subfoveal location have potential direct toxic effects on RPE and photoreceptors. Additionally, subretinal PFCL prevents anatomical reattachment of the fovea. It is recommended that subfoveal PFCL persisting after vitreoretinal surgery be removed if central visual acuity is reduced, because surgical aspiration may result in serious complications $[66,67]$.

Dome-shaped macula (Figure 3E): The dome-shaped macula was firstly described by Gaucher et al using OCT findings in 2008. Domeshaped macula is characterized by the configuration of the macula anteriorly, macular convexity and dome into the vitreous cavity of the macula. Ophthalmoscopy could not effectively reveal this entity and OCT may need for the diagnosis. It may be observe in high myopia and posterior staphyloma. It may be associated with serous retinal detachment, RPE detachment and CNVM. It is not well-known its pathogenic mechanism. Its bilaterality rate is $50-80 \%[68,69]$.

Brush border pattern (Figure 3E): Waste products of photoreceptors are removed by RPEs via phagocytosis. In CSCR, subretinal fluid and serous macular detachment cause loss of the contact between photoreceptor outer segments and RPEs and the accumulation of the waste products in photoreceptor outer segments an also the elongation of photoreceptor outer segments. This provides an irregular appearance of detached neurosensory retina. In OCT, this appearance is described as "brush border pattern". Brush border pattern may seem in chronical cases. However, it may occur in the early stage of a fresh serous macular detachment [61,70-73].

Cystoid foveal degeneration (Figure 3F): Cystoid foveal degeneration (CFD) may occur in diabetic maculopathy, RVO, uveitis, AMD and CSCR. It is characterized by large cystic spaces or sometimes giant single cyst with thinned septae or without septa in fovea. The 
distortion of ISOS band or the loss of photoreceptor outer segments may be associated with this pathology. CME has lesser and smaller cysts than those in CFD. The most important feature distinguishing finding in CFD is that the remaining retinal tissue outside of CFD is very little. This finding shows that visual prognosis is poor compared to CME. Although the cysts in CFD may shrink or disappear, the improvement in visual acuity is limited. CFD may be related a longstanding pathogenic process or recurrent foveal ischemia. FFA often fails for the distinguishing from CME. This pathology may be accurately diagnosed with OCT $[74,75]$.

\section{Authorship and contribution}

All authors listed on the title page made significant contributions to this manuscript.

\section{Acknowledgements}

None

\section{Funding}

No funding was received for this study.

\section{Competing interest}

The authors have no conflict of interest or financial relationships related to this manuscript.

\section{References}

1. Arevalo JF, Lasave AF, Arias JD, Serrano MA, Arevalo FA (2013) Clinical applications of optical coherence tomography in the posterior pole: the 2011 José Manuel Espino Lecture - Part I. Clin Ophthalmol 7: 2165-2179. [Crossref]

2. Gabriele ML, Wollstein G, Ishikawa H, Kagemann L, Xu J, et al. (2011) Optical coherence tomography: history, current status, and laboratory work. Invest Ophthalmol Vis Sci 52: 2425-2436. [Crossref]

3. Spaide RF, Curcio CA (2011) Anatomical correlates to the bands seen in the outer retina by optical coherence tomography: Literature review and model. Retina 31: 1609-1619. [Crossref]

4. Mitamura Y, Mitamura-Aizawa S, Katome T, Naito T, Hagiwara A, et al. (2013) Photoreceptor impairment and restoration on optical coherence tomographic image. $J$ Ophthalmol 2013: 518170. [Crossref]

5. Sakai T, Calderone JB, Lewis GP, Linberg KA, Fisher SK, et al (2003) Cone photoreceptor recovery after experimental detachment and reattachment: An immunocytochemical, morphological, and electrophysiological study. Invest Ophthalmol Vis Sci 44:416-425. [Crossref]

6. Milam A, Li Z, Cideciyan A, Jacobson S (1996) Clinicopathologic effects of the Q64ter rhodopsin mutation in retinitis pigmentosa. Invest Ophthalmol Vis Sci 37:753-765. [Crossref]

7. Aizawa S, Mitamura Y, Hagiwara A, Sugawara T, Yamamoto S (2010) Changes of fundus autofluorescence, photoreceptor inner and outer segment junction line, and visual function in patients with retinitis pigmentosa. Clin Experiment Ophthalmol 38:597-604. [Crossref]

8. Hagiwara A, Mitamura Y, Kumagai K, Baba T, Yamamoto S (2013) Photoreceptor impairment on optical coherence tomographic images in patients with retinitis pigmentosa. Br J Ophthalmol 97: 237-238. [Crossref]

9. Kwon Y, Lee D, Kim H, Kwon O (2014) Predictive findings of visual outcome in spectral domain optical coherence tomography after ranibizumab treatment in agerelated macular degeneration. Korean J Ophthalmol 28: 386-92. [Crossref]

10. Oishi A, Shimozono M, Mandai M, Hata M, Nishida A, et al. (2013) Recovery of photoreceptor outer segments after anti-VEGF therapy for age-related macular degeneration. Graefes Arch Clin Exp Ophthalmol 251: 435-440. [Crossref]

11. Theodossiadis P, Grigoropoulos V, Theodossiadis G (2011) The significance of the external limiting membrane in the recovery of photoreceptor layer after successful macular hole closure: A study by spectral domain optical coherence tomography. Ophthalmologica 225:176-184. [Crossref]
12. Bottoni F, De Angelis S, Luccarelli S, Cigada M, Staurenghi G (2011) The dynamic healing process of idiopathic macular holes after surgical repair: a spectral-domain optical coherence tomography study. Invest Ophthalmol Vis Sci 52: 4439-4446. [Crossref]

13. Ooka E, Mitamura Y, Baba T, Kitahashi M, Oshitari T, Yamamoto S (2011) Fovea microstructure on spectral-domain optical coherence tomographic images and visual function after macular hole surgery. Am J Ophthalmol 152: 283-290. [Crossref]

14. Shimozono M, Oishi A, Hata M, Kurimoto Y (2011) Restoration of the photoreceptor outer segment and visual outcomes after macular hole closure: Spectral-domain optical coherence tomography analysis. Graefes Arch Clin Exp Ophthalmol 249: 1469-1476. [Crossref]

15. Wakabayashi T, Oshima Y, Fujimoto H, Murakami Y, Sakaguchi H, et al. (2009) Foveal microstructure and visual acuity after retinal detachment repair: imaging analysis by Fourier-domain optical coherence tomography. Ophthalmology 116: 519-528. [Crossref]

16. Wakabayashi T, Fujiwara M, Sakaguchi H, Kusaka S, Oshima Y (2010) Foveal microstructure and visual acuity in surgically closed macular holes: Spectral-domain optical coherence tomographic analysis. Ophthalmology 117:1815-1824. [Crossref]

17. Shimozono M, Oishi A, Hata M, Matsuki T, Ito S, et al. (2012) The significance of cone outer segment tips as a prognostic factor in epiretinal membrane surgery. $\mathrm{Am} \mathrm{J}$ Ophthalmol 153: 698-704. [Crossref]

18. Itoh Y, Inoue M, Rii T, Hirota K, Hirakata A (2013) Correlation between foveal cone outer segment tips line and visual recovery after epiretinal membrane surgery. Invest Ophthalmol Vis Sci 54:7302-7308. [Crossref]

19. Saxena S, Srivastav K, Cheung CM, Ng JY, Lai TY (2014) Photoreceptor inner segment ellipsoid band integrity on spectral domain optical coherence tomography. Clin Ophthalmol 8: 2507-2522. [Crossref]

20. Zweifel SA, Imamura Y, Freund KB, Spaide RF (2011) Multimodal fundus imaging of pseudoxanthoma elasticum. Retina 31: 482-491. [Crossref]

21. Kojima H, Otani A, Ogino K, Nakagawa S, Makiyama Y, et al. (2012) Outer retinal circular structures in patients with Bietti crystalline retinopathy. Br J Ophthalmol 96: 390-393. [Crossref]

22. Turgut B, Bilir N (2012) The frequency and importance of outer retinal tubulations in age related macular degeneration. Retina-Vitreus 20: 260-264.

23. Goldberg NR, Greenberg JP, Laud K, Tsang S, Bailey Freund K (2013) Outer Retinal Tubulation in Degenerative Retinal Disorders. Retina 33: 1871-1876. [Crossref]

24. Cohen SY, Dubois L, Nghiem-Buffet S, Ayrault S, Fajnkuchen F, et al. (2010) Retinal pseudocysts in age-related geographic atrophy. Am J Ophthalmol 150: 211-217. [Crossref]

25. Wolter JR (1955) [A case of advanced retinitis pigmentosa with rosette-shaped formations on the retina]. Klin Monbl Augenheilkd Augenarztl Fortbild 127: 687-694. [Crossref]

26. Coscas G, Coscas F, Vismara S, Zourdani A, Li Calzi CI (2009) Clinical features and natural history of AMD; in Coscas G, Coscas F, Vismara S, Zourdani A, Li Calzi CI (Eds): Optical Coherence Tomography in Age-Related Macular Degeneration. Heidelberg, Springer, pp 171-174.

27. Coscas G, De Benedetto U, Coscas F, Li Calzi CI, Vismara S, et al (2013) Hyperreflective dots: a new spectral-domain optical coherence tomography entity for follow-up and prognosis in exudative age-related macular degeneration. Ophthalmologica 229: 32-37.

28. Coscas G, Loewenstein A, Augustin A, Bandello F, Battaglia Parodi M, et al. (2011) Management of retinal vein occlusion--consensus document. Ophthalmologica 226 4-28. [Crossref]

29. Ogino K, Murakami T, Tsujikawa A, Miyamoto K, Sakamoto A, et al. (2012) Characteristics of optical coherence tomographic hyperreflective foci in retinal vein occlusion. Retina 32: 77-85. [Crossref]

30. Bolz M, Schmidt-Erfurth U, Deak G, Mylonas G, Kriechbaum K, et al (2009) Optical coherence tomographic hyper-reflective foci: a morphological sign of lipid extravasation in diabetic macular edema. Ophthalmology 116: 914-920.

31. Kon Y, Iida T, Maruko I, Saito M (2008) The optical coherence tomographyophthalmoscope for examination of central serous chorioretinopathy with precipitates. Retina 28: 864-869. [Crossref]

32. van Velthoven ME, Verbraak FD, Garcia PM, Schlingemann RO, Rosen RB, et al (2005) Evaluation of central serous retinopathy with en face optical coherence tomography. $\mathrm{Br}$ J Ophthalmol 89: 1483-1488. [Crossref] 
33. Vujosevic S, Bini S, Midena G, Berton M, Pilotto E, et al (2013) Hyperreflective intraretinal spots in diabetics without and with nonproliferative diabetic retinopathy: an in vivo study using spectral domain OCT. J Diabetes Res.

34. Gaudric A, Ducos de Lahitte G, Cohen SY, Massin P, Haouchine B (2006) Optical coherence tomography in group 2A idiopathic juxtafoveolar retinal telangiectasis. Arch Ophthalmol 124: 1410-1419. [Crossref]

35. Baumüller S, Charbel Issa P, Scholl HP, Schmitz-Valckenberg S, Holz FG (2010) Outer retinal hyperreflective spots on spectral-domain optical coherence tomography in macular telangiectasia type 2. Ophthalmology 117: 2162-2168. [Crossref]

36. Uji A, Murakami T, Nishijima K, Akagi T, Horii T, et al. (2012) Association between hyperreflective foci in the outer retina, status of photoreceptor layer, and visual acuity in diabetic macular edema. Am J Ophthalmol 153: 710-717, 717. [Crossref]

37. Framme C, Schweizer P, Imesch M, Wolf S, Wolf-Schnurrbusch U (2012) Behavior of SD-OCT-detected hyperreflective foci in the retina of anti-VEGF-treated patients with diabetic macular edema. Invest Ophthalmol Vis Sci 24: 5814-5818. [Crossref]

38. Omri S, Behar-Cohen F, de Kozak Y, Sennlaub F, Verissimo LM, et al (2011) Microglia/ macrophages migrate through retinal epithelium barrier by a transcellular route in diabetic retinopathy: role of PKC in the Goto Kakizaki rat model. Am J Pathol 179: 942-953. [Crossref]

39. Fong AH, Li KK, Wong D (2011) Choroidal evaluation using enhanced depth imaging spectral-domain optical coherence tomography in Vogt-Koyanagi-Harada disease. Retina 31: 502-509. [Crossref]

40. Turgut B, Yildirim H (2015) The causes of hyperreflective dots in optical coherence tomography excluding diabetic macular edema and retinal venous occlusion. Open Ophthalmol J 9: 36-40. [Crossref]

41. Chen E, Brown DM, Benz MS, Fish RF, Wong TP, et al. (2010) Spectral domain optical coherence tomography as an effective screening test for hydroxychloroquine retinopathy (the "flying saucer" sign). Clin Ophthalmol 4: 1151-1158. [Crossref]

42. Pandya HK, Robinson M, Mandal N, Shah VA (2015) Hydroxychloroquine retinopathy: A review of imaging. Indian J Ophthalmol 63: 570-574. [Crossref]

43. Turgut B, Koca SS (2012) Perifoveal cupping detected by optical coherence tomography may represent an early sign of antimalarial-associated maculopathy. Firat Medical Journal (Firat Tip Dergisi) 17; 238-242.

44. Pihos AM (2015) Broadened Foveal Base Detected by Spectral Domain Optical Coherence Tomography-A Case Series in Patients on Hydroxychloroquine Therapy. Illinois College of Optometry, Research presentations.http://www.ico.edu/wp-content uploads/2016/01/Research-Posters-2015-Interactive.pdf

45. Jampol LM, Shankle J, Schroeder R, Tornambe P, Spaide RF, et al. (2006) Diagnostic and therapeutic challenges. Retina 26: 1072-1076. [Crossref]

46. Margolis R, Mukkamala SK, Jampol LM, Spaide RF, Ober MD, et al. (2011) The expanded spectrum of focal choroidal excavation. Arch Ophthalmol 129: 1320-1325. [Crossref]

47. Liu GH, Lin B, Sun XQ, He ZF, Li JR, et al. (2015) Focal choroidal excavation: a preliminary interpretation based on clinic and review. Int $J$ Ophthalmol 8: 513-521. [Crossref]

48. Shinojima A, Kawamura A, Mori R, Yuzawa M (2014) Morphologic features of focal choroidal excavation on spectral domain optical coherence tomography with simultaneous angiography. Retina 34: 1407-1414. [Crossref]

49. Pierro L, Casalino G, Introini U, Gagliardi M, Sergenti J, et al (2015) Natural course of symptomatic focal choroidal excavation. Ophthalmic Surg Lasers Imaging Retina 46: 125-130. [Crossref]

50. Xu H, Zeng F, Shi D, Sun X, Chen X, et al. (2014) Focal choroidal excavation complicated by choroidal neovascularization. Ophthalmology 121: 246-250. [Crossref]

51. Lim FP, Wong CW, Loh BK, Chan CM, Yeo I, et al (2015) Prevalence and clinical correlates of focal choroidal excavation in eyes with age-related macular degeneration, polypoidal choroidal vasculopathy and central serous chorioretinopathy. $\mathrm{Br} J$ Ophthalmol.

52. Esfahani MR, Esfahani HR, Mahmoudi A, Johari MK, Hemati K (2015) Focal Choroidal Excavation in Best Vitelliform Macular Dystrophy: Case Report. $J$ Clin Diagn Res 9: ND01-02. [Crossref]
53. Mercan K, Turgut B, Ünesi E, Çatak O (2015) Torpedo maculopathy: A case report. New Front Ophthalmol 1: 29-31.

54. Nishikawa Y, Fujinami K, Watanabe K, Noda T, Tsunoda K, et al. (2014) Clinical course of focal choroidal excavation in Vogt-Koyanagi-Harada disease. Clin Ophthalmol 8: 2461-2465. [Crossref]

55. Ohki T, Sakai T, Tsuneoka H (2015) Focal choroidal excavation associated with focal retinochoroiditis. Optom Vis Sci 92: e12-20. [Crossref]

56. Hashimoto Y, Saito W, Noda K, Ishida S (2014) Acquired focal choroidal excavation associated with multiple evanescent white dot syndrome: observations at onset and a pathogenic hypothesis. BMC Ophthalmol 14:135. [Crossref]

57. Kim H, Woo SJ, Kim YK, Lee SC, Lee CS (2015) Focal Choroidal Excavation in Multifocal Choroiditis and Punctate Inner Choroidopathy. Ophthalmology 122: 1534 1535. [Crossref]

58. Sivalingam MD, Say EA, Shields CL (2015) Evolution of focal choroidal excavation underlying combined hamartoma of the retina and retinal pigment epithelium in a child. J AAPOS 19: 379-381. [Crossref]

59. Kou S, Rett D (2015) Various SD-OCT features of focal choroidal excavations. Optom Vis Sci 92: S59-66. [Crossref]

60. Khalil M, Malik TG, Chaudhary QL, Shafiq MM (2015) Angiographic Patterns and Tomographic findings in Central Serous Chorioretinopathy revisited. PJ M H S 9:14091412 .

61. Turgut B, Ergen I (2013). Santral seröz koryoretinopatinin optik koherens tomografik paternleri (Optical Coherence Tomographic Patterns of Central Serous Chorioretinopathy). Firat Medical Journal (Firat Tip Dergisi) 18: 39-43.

62. Lima LH, Laud K, Chang LK, Yannuzzi LA (2011) Choroidal macrovessel. $B r J$ Ophthalmol 95: 1333-1334. [Crossref]

63. Choudhry N, Rao RC (2016) Enhanced depth imaging features of a choroida macrovessel. Retin Cases Brief Rep 10: 18-21. [Crossref]

64. Gelman SK, Freund KB, Shah VP, Sarraf D (2014) The pearl necklace sign: a novel spectral domain optical coherence tomography finding in exudative macular disease. Retina 34: 2088-2095. [Crossref]

65. Kim HK, Rho CR, Lee WK, Kim KS (2008) Optical Coherence Tomography Findings in Best Disease. J Korean Ophthalmol Soc 9: 845-852. [Crossref]

66. Roth DB, Sears JE, Lewis H (2004) Removal of retained subfoveal perfluoro-n-octane liquid. Am J Ophthalmol 138: 287-289. [Crossref]

67. Lesnoni G, Rossi T, Gelso A (2004) Subfoveal liquid perfluorocarbon. Retina 24: 172 176. [Crossref]

68. Gaucher D, Erginay A, Lecleire-Collet A, Haouchine B, Puech M, et al. (2008) Domeshaped macula in eyes with myopic posterior staphyloma. Am J Ophthalmol 145: 909914. [Crossref]

69. Cebeci Z, Kir N (2015) Bilateral Dome-Shaped Macula with Serous Macular Detachment in a Child. Case Rep Ophthalmol Med 2015: 213968. [Crossref]

70. Kon Y, Iida T, Maruko I, Saito M (2008) The optical coherence tomographyophthalmoscope for examination of central serous chorioretinopathy with precipitates. Retina 28: 864-869. [Crossref]

71. Yaylacioglu-Tuncay F, Gürelik G (2010) Santral Seröz Koryoretinopati (Central serous chorioretinopathy). Retina-Vitreus 18: 85-111.

72. Teke MY, Elgin U, Nalcacioglu-Yuksekkaya P, Sen E, Ozdal P, et al. (2014) Comparison of autofluorescence and optical coherence tomography findings in acute and chronic central serous chorioretinopathy. Int J Ophthalmol 7: 350-354. [Crossref]

73. Matsumoto H, Kishi S, Otani T, Sato T (2008) Elongation of photoreceptor outer segment in central serous chorioretinopathy. Am J Ophthalmol 145: 162-168. [Crossref]

74. Iida T, Yannuzzi LA, Spaide RF, Borodoker N, Carvalho CA, et al. (2003) Cystoid macular degeneration in chronic central serous chorioretinopathy. Retina 23: 1-7. [Crossref]

75. Özdemir H, Arf S, Karaçorlu M (2015) Maküla hastaliklarinda optik koherens tomografi. Günes Kitabevi.

Copyright: (C2016 Turgut B. This is an open-access article distributed under the terms of the Creative Commons Attribution License, which permits unrestricted use, distribution, and reproduction in any medium, provided the original author and source are credited. 